\title{
Phytochemical composition, antioxidant activity and cytotoxicity of Blumea lacera Linn. from two different habitats
}

\author{
Fakhruddin Ali Ahmed*, Anisur Rahman and Sanzida Mubassara \\ Department of Botany, Jahangirnagar University, Savar, Dhaka-1342, Bangladesh.
}

\begin{abstract}
Blumea lacera collected from JU campus and the Sundarbans showed strong presence of carbohydrates, flavonoids, trace amount of alkaloids, weak presence of some glucosides, terpenoids and steroids following preliminary phytochemical screening. DPPH free radical scavenging activity increased with the increase of concentration of methanol, ethyl acetate and $n$-hexane fractions of both the samples. Methanol and ethyl acetate fractions of JU sample showed strong scavenging activity of DPPH free radical. Concentration dependent increment in percent mortality of brine shrimp nauplii was observed in all the fractions of both the samples. Ethyl acetate and methanol fractions of JU sample showed less cytotoxicity than that of Sundarbans samples. Therefore, methanol and ethyl acetate fractions of JU sample should be the choice to identify new bioactive compound(s) in the future.
\end{abstract}

Key words: Phytochemicals, antioxidant activity, cytotoxicity, Blumea lacera, mangrove habitat

\section{INTRODUCTION}

Habitat is the natural environment in which an organism lives or the physical environment that surrounds a species population (Dickinson, 1963; Abercrombie et al., 1966). Plants growing in different habitat or ecological condition may evolve through stable genetic polymorphisms and produce diverse secondary metabolites (Binns, 2002). Blumea lacera Linn. is one of the most common weeds of Bangladesh. It is a small size annual herb belongs to the family Asteraceae commonly known as Janglimulli, Kakaronda, Siyalmutra and Susksampatra. The plant has an enormous medicinal value and been widely used in the traditional medicinal system of Bangladesh for a long time. The plant is used as antipyretic, stimulant, astringent, anthelmintic, febrifuge, diuretic and to treat hemorrhoids (Pandit et al., 1996), bonchitis (Jha and Verma, 1996), sores and wound healing (Ahluwalia, 1968). The root is used as blood purifier while leaves are used to rectify urinary complaints (Varandani, 1969). Seeds of this plant have been reported to exhibit antibacterial activity (Gayake, 2012).

As one of the geographically-widespread species, B. lacera has adapted naturally to different habitats in Bangladesh including mangroves. Many workers reported on the presence and isolation of bioactive compounds from B. lacera that are found in mesophytic habitat (Agarwal et al., 1995; Rao et al., 1977). But there is no information

* Author to whom all correspondence should be made. 
on the phytochemical composition and bioactivity of this plant grows in mangrove habitat. Thus the present investigation aims to a comparative study on phytoconstituents, DPPH free radical scavenging activity and cytotoxicity of $B$. lacera growing in two different ecological conditions namely, meshophytic and mangrove habitats.

\section{MATERIALS AND METHODS}

Plant material: The aerial parts of the plants were collected from JU campus and from the yard Kalagachia Range office, The Sundarbans, Khulna, Bangladesh and The plant was finally identified as Blumea lacera by the Bangladesh National Herbarium (BNH), Mirpur, Dhaka, Bangladesh. The voucher specimens (accession no. of JU sample: DACB38210 and for Sundarbans sample: DACB32624) have been deposited in the Bangladesh National Herbarium (BNH), Mirpur, Dhaka, Bangladesh for further reference.

Preparation of crude extract and fraction: The collected plant parts (aerial parts) were sun-dried followed by drying in a hot air oven (Gallenkamp) at reduced temperature $\left(<50^{\circ} \mathrm{C}\right)$ for 4 days to make suitable for grinding purpose. About $200 \mathrm{~g}$ powder was digested with $1000 \mathrm{ml}$ of $100 \%$ methanol for three days accompanying with occasional shaking and stirring. The whole mixtures then underwent a coarse filtration by a piece of clean, white cotton material followed by filtration using Whatman filter paper. The extract was concentrated at $45^{\circ} \mathrm{C}$ under reduced pressure using a rotary evaporator and resultant residue was stored under refrigerated conditions until further studies.

Partition of the crude methanolic extract: Solvent-solvent partitioning was done by using the protocol designed by Kupchan \& Tsou (1973) and modified version of Wagenen et al. (1993). The crude methanolic extract of the sample was first partitioned with $n$ - hexane and mthanol at ratio 1:1 using separating funnel and these two fractions were evaporated separately to dryness by rotary evaporator at $40^{\circ} \mathrm{C}$. Then the mthanol fraction was further partitioned to ethyl acetate and methanol fractions and evaporated to dryness. Fraction samples were then marked and stored in dark, cold and dry place.

Phytochemical screening: The crude methanolic extract and the fractions were subjected to different qualitative tests to find out the presence of chemical constituents using standard procedure (Evans, 1989; Sofowara, 1993; Ghani, 1998 and Dev, 2002). Molisch's and Fehling's reagents were used to investigate the presence of carbohydrates and reducing sugar, respectively. Hagger's reagent, Wagner's reagent, Mayer's reagent and Dragendroff's reagents were used to test the presence of alkaloids while $\mathrm{FeCl}_{3}$ test and Keller Killiani's test were carried out for glycosides and cardenolides, respectively. Borntrager's test was conducted to test the presence of anthraquinone glycosides; Lead acetate, Alkali, $\mathrm{FeCl}_{3}$ and Conc. $\mathrm{H}_{2} \mathrm{SO}_{4}$ were used for flavonoids. $\mathrm{FeCl}_{3}$, ammonia and lead acetate were used to test the presence of phenolic compounds. Concentrated $\mathrm{H}_{2} \mathrm{SO}_{4}$ was used to detect terpenoids whereas acetic anhydride was used to check the presence of triterpene. The presence of phytosterols/steroids was indicated by the Salkowski's test while the presence of saponins was confirmed by foam test. 
Determination of antioxidant activity: The antioxidant activities of the extracts were measured on the basis of the scavenging activity of the stable 1,1-diphenyl-2picrylhydrazyl (DPPH) free radical following the method described by Blois, (1958) and Aoshima et al., 2004. $150 \mu \mathrm{l}$ DPPH solution was added to $3 \mathrm{ml}$ methanol and absorbance was taken immediately at $517 \mathrm{~nm}$ for control reading. $50 \mu \mathrm{l}$ of various concentrations of different fractions as well as standard compound (ascorbic acid) were taken and the volume was made uniformly to $150 \mu \mathrm{l}$ using methanol. Each of the samples was then further diluted with methanol up to $3 \mathrm{ml}$ and to each $150 \mathrm{ml}$ DPPH was added. Finally, absorbance at $517 \mathrm{~nm}$ was determined after $30 \mathrm{~min}$. and the percent inhibition activity was calculated as

DPPHfree radicalscavengingactivity $(\%)=\frac{\text { controlabsorption- } \text { correctedsampleabsorption }}{\text { controlabsorption }} \times 100$

$\mathrm{IC}_{50}$ values (concentration of sample required to scavenge $50 \%$ of free radicals) were calculated following the method of Brand-Williams et al. (1995).

Brine shrimp lethality bioassay: Brine shrimps (Artemia salina) lethality bioassay was followed by Meyer et al. (1982).

\section{RESULTS AND DISCUSSION}

Blumea lacera is a common weed found throughout the Bangladesh. Traditional use of this plant inspired to investigate the phytochemical composition along with some selected bioactivity of the aerial parts of $B$. lacera. The crude methanolic extract of both the sample collected from JU campus and the Sundarbans were first partitioned into $n$-hexane and methanol, the methanol fraction was further partitioned into ethyl acetate and water. Then all fractions were marked and stored in dark, cold and dry place. JU sample and the sundarbans samples yielded $51.43 \%$ and $56 \%$ methanolic crude extract, respectively. The results of fraction amount obtained from methanolic crude extract have been presented in Table 1. The yield percentage was higher in JU sample compared to Sundarbans sample for $n$-hexane and ethyl acetate fractions. After partitioning the yield of $n$-hexane fractions were $47.14 \%$ (JU sample) and 38\% (Sundarbans sample). Whereas the yield of ethyl acetate fractions were $41.12 \%$ and $35.71 \%$ for JU and Sundarbans samples, respectively (Table 1).

Table 1. Yield of fractions of B. lacera collected from JU campus and the Sundarbans

\begin{tabular}{|c|c|c|c|}
\hline \multicolumn{2}{|c|}{ Fractions } & $\begin{array}{l}\text { JU sample } \\
\text { (\% yield) }\end{array}$ & $\begin{array}{c}\text { Sundarbans } \\
\text { sample } \\
\text { (\% yield) }\end{array}$ \\
\hline \multicolumn{2}{|c|}{ Methanolic crude extract } & 51.43 & 56 \\
\hline Partition of methanolic crude & $n$-Hexane fraction & 47.14 & 38 \\
\hline extract & Methanol fraction & 50.27 & 60.09 \\
\hline Further partition of methanol & Ethyl acetate fraction & 41.12 & 35.71 \\
\hline fraction & Water fraction & 55 & 62 \\
\hline
\end{tabular}


The data of qualitative chemical examination of Blumea lacera collected from JU campus and the Sundarbans have been presented in Table 2. Phytochemical analysis of the aerial parts showed the presence of various phytochemicals of therapeutic significance. The qualitative chemical examination of fractions obtained by successive solvent extraction of the aerial parts were found to contain carbohydrates, flavonoids, trace amount of alkaloids, some glucosides, terpenoids and steroids in the polar fractions collected from JU campus and Sundarbans (Table 2). These phytoconstituents present in the extracts may account for their various pharmacological activities (Ghani, 2003). Pattewar et al. (2012) reported that $B$. lacera contains tannins, alkaloids, saponins, anthraquinone glycosides, steroids, flavonoids, phenolics and terpenoids from the aqueous extract of B. lacera. Tiwari et al. (2012) also reported the presence of carbohydrates, alkaloids, glycosides, phytosterols, phenolic compounds and flavonoids from this plant. Whereas, Pratap \& Parthasarathy (2012) reported that B. lacera contains steroids, terpenoids, alkaloids, saponin and absence of tannins and phenolic compounds.

Natural products are beneficial to physiological health (Hossain et al., 2008). It has long been recognized that naturally occurring substances in higher plants have antioxidant activity and increasing attention has been focused on medicinal plants. DPPH free radical scavenging is a popular and reliable method for screening the free radical scavenging activity of compounds or antioxidant capacity of the plant extracts (Espin et al., 2000). The DPPH free radical scavenging of antioxidant assay is based on the ability of 1, 1diphenyl-2-picrylhydrazyl (DPPH), a stable free radical, to decolorize in the presence of antioxidants (Kumarasamy et al., 2007).

In the present investigation, the highest value $(96.33 \%)$ of DPPH free radical scavenging activity at $200 \mu \mathrm{g} / \mathrm{ml}$ concentration was observed in the methanol fraction of JU sample. The ethyl acetate fraction of the Sundarbans sample showed $93.47 \%$ scavenging activity at the concentration of $200 \mu \mathrm{g} / \mathrm{ml}$, followed by methanol $(79.07 \%)$ and $n$-hexane (66.16\%) fractions, respectively. On the other hand the $n$-hexane fraction of JU sample of B. lacera showed the lowest value $(60.32 \%)$ for free radical scavenging activity (Table $3)$. In both the samples free radical scavenging activity was found to increase with concentration of the fractions. But the increasing trends varied depending on fractions. Bhaumik et al. (2008) reported that the methanol fraction of B. lanceolaria exhibited significant DPPH free radical scavenging activity with an $\mathrm{IC}_{50}$ value of $45.79 \mu \mathrm{g} / \mathrm{ml}$ whereas the $\mathrm{IC}_{50}$ value of the standard drug L-ascorbic acid was found to be $13.76 \mu \mathrm{g} / \mathrm{ml}$. Roy et al., (2012) reported that the ethyl acetate and aqueous soluble fraction of $B$. membranacea showed mild to moderate free radical scavenging activity. Prajakta $e t$ al. (2013) reported that the essential oil of B. eriantha showed DPPH free radical scavenging with $\mathrm{IC}_{50}$ value of $437.92 \mu \mathrm{g} / \mathrm{ml}$.

Brine Shrimp Cytotoxicity Test (BSCT) is a useful tool to screen a wide range of chemical compounds for their various bioactivities. It has been well utilized to screen and fractionation of physiologically active plant extracts as well. Table 4 showed the lethality of the three fractions of the aerial parts of B. lacera collected from JU campus and the Sundarban to the Brine Shrimp nauplii. Concentration dependent increment in percent 
mortality of Brine Shrimp nauplii was observed in all the fractions of both the samples. Ethyl acetate and methanol fractions of the Sundarbans samples showed the higher cytotoxicity compared to JU sample. JU sample showed relatively increased toxicity than the Sundarbans sample only for $n$-hexane fraction. LC $_{50}$ value $115.38 \mu \mathrm{g} / \mathrm{ml}$ of $n$-hexane fraction indicates the presence of cytotoxic compounds in the extract. $\mathrm{LC}_{50}$ values of $n$ hexane fraction of the Sundarbans sample was $181.53 \mu \mathrm{g} / \mathrm{ml} . \mathrm{LC}_{50}$ values of methanol fraction of JU and the Sundarbans samples were $183.80 \mu \mathrm{g} / \mathrm{ml}$ and $133.41 \mu \mathrm{g} / \mathrm{ml}$, respectively whereas that was for ethyl acetate fraction of JU and the Sundarbans samples were $245.43 \mu \mathrm{g} / \mathrm{ml}$ and $159.82 \mu \mathrm{g} / \mathrm{ml}$, respectively. In comparison with vincristine sulphate $\left(\mathrm{LC}_{50}=0.069 \mu \mathrm{g} / \mathrm{ml}\right)$ the results were very poor. Preliminary phytochemical screening revealed the presence of steroids and trace amount of alkaloids. So the observed cytotoxic action may be due to the presence of such compounds.

Roy et al. (2012) reported that in Brine shrimp lethality bioassay, the petroleum ether soluble fraction of $B$. membranacea showed the maximum toxicity towards the shrimp with $\mathrm{LC}_{50}$ value of $0.841 \mu \mathrm{g} / \mathrm{ml}$ whereas the standard drug vincristine sulphated showed the $\mathrm{LC}_{50}$ value of $0.544 \mu \mathrm{g} / \mathrm{ml}$. Zhu \& Tian (2011) reported that the essential oil of $B$. martiniana showed the significant larvicidal activity and it also showed a dose dependent effect on mortality. Moshi et al., (2010) reported that the ethanol fraction of B. auriculata showed significant mildy cytotoxic activity with the $\mathrm{LC}_{50}$ value of $41.80 \mu \mathrm{g} / \mathrm{ml}$. Uddin et al.(2011) reported that the methanol fraction of $B$. lacera showed the maximum cytotoxicity with $\mathrm{LC}_{50}$ values of 0.01 to $0.08 \mathrm{mg} / \mathrm{ml}$ against healthy mouse fibroblast and three human cancer cell lines. 
Ahmed et al.

Table 2. Qualitative chemical examination of aerial parts of Blumea lacera collected from two different habitats

\begin{tabular}{|c|c|c|c|c|c|c|c|c|c|}
\hline \multicolumn{3}{|c|}{ Name of the test } & \multirow[t]{2}{*}{ Specific test } & \multicolumn{2}{|c|}{$n$-Hexane fraction } & \multicolumn{2}{|c|}{ Ethyl acetate fraction } & \multicolumn{2}{|c|}{ Methanol fraction } \\
\hline \multicolumn{3}{|c|}{ Name or the test } & & & & & sample & & Sampie \\
\hline \multirow{2}{*}{\multicolumn{2}{|c|}{ Carbohydrates test }} & a. & Molicsh's & - & - & + & + & + & + \\
\hline & & b. & Fehling's & + & + & + & + & + & ++ \\
\hline \multirow{4}{*}{\multicolumn{2}{|c|}{ Alkaloids test }} & a. & Hager's & - & - & + & + & + & + \\
\hline & & b. & Wagner's & - & - & - & + & + & + \\
\hline & & & Mayer's & - & - & - & - & - & - \\
\hline & & d. & $\begin{array}{l}\text { Tannic acid } \\
(10 \%)\end{array}$ & + & + & + & + & + & + \\
\hline \multirow{4}{*}{\multicolumn{2}{|c|}{ Flavonoids test }} & a. & Ferric chloride & - & - & - & - & - & - \\
\hline & & b. & Lead acetate & - & - & ++ & + & ++ & + \\
\hline & & c. & Alkali & - & - & ++ & + & + & - \\
\hline & & d. & Con. $\mathrm{H}_{2} \mathrm{SO}_{4}$ & - & - & - & - & - & - \\
\hline \multirow[t]{3}{*}{$\begin{array}{l}\text { Glycosides } \\
\text { test }\end{array}$} & Common test & a. & $\begin{array}{l}\text { Ferric } \\
\text { chloride }\end{array}$ & - & - & + & + & - & - \\
\hline & $\begin{array}{l}\text { Anthraquinon } \\
\text { glycosides }\end{array}$ & b. & Borntrager's & + & + & - & - & + & + \\
\hline & Cardiac glycosides & c. & Keller killiani & - & - & - & - & - & - \\
\hline \multirow{3}{*}{\multicolumn{2}{|c|}{$\begin{array}{l}\text { Test for Tannins and Phenolic } \\
\text { compounds }\end{array}$}} & a. & Ferric chloride & - & - & - & - & - & - \\
\hline & & b. & Lead acetate & - & - & - & - & ++ & + \\
\hline & & c. & Amonia $\left(\mathrm{NH}_{3}\right)$ & - & - & - & - & - & - \\
\hline \multicolumn{2}{|c|}{ Saponin test } & a. & Foam & - & - & - & - & - & ++ \\
\hline \multicolumn{2}{|c|}{ Terpenoid Common test } & a. & Con. $\mathrm{H}_{2} \mathrm{SO}_{4}$ & - & - & - & - & - & - \\
\hline \multicolumn{2}{|r|}{ Triterpenoids test } & b. & $\begin{array}{l}\text { Acetic } \\
\text { anhydride }\end{array}$ & - & - & - & - & - & - \\
\hline \multicolumn{2}{|c|}{ Phytosterol/Steroid test } & a. & Salkowski & + & + & + & + & ++ & ++ \\
\hline
\end{tabular}

NB: +++ =Strong, $++=$ moderate,$+=$ week, $-=$ Negative 
Phytochemical composition, antioxidant activity and cytotoxicity of Blumea lacera Linn.

43

Table 3. DPPH free radical scavenging activity of $B$. lacera collected from JU campus and the Sundarbans

\begin{tabular}{|c|c|c|c|c|c|c|}
\hline \multirow{3}{*}{$\begin{array}{l}\text { Concentration } \\
(\mu \mathrm{g} / \mathrm{ml})\end{array}$} & \multicolumn{6}{|c|}{ Activity (\%) } \\
\hline & \multicolumn{2}{|c|}{$n$-Hexane } & \multicolumn{2}{|c|}{ Ethyl acetate } & \multicolumn{2}{|c|}{ Methanol } \\
\hline & JU sample & $\begin{array}{c}\text { Sundarbans } \\
\text { sample }\end{array}$ & JU sample & $\begin{array}{c}\text { Sundarbans } \\
\text { sample }\end{array}$ & JU sample & Sundarbans sample \\
\hline 5 & $2.12(f) \pm 0.56$ & $5.12(\mathrm{f}) \pm 0.10$ & $57.51(\mathrm{e}) \pm 0.41$ & $12.76(\mathrm{e}) \pm 1.12$ & $65.33(d) \pm 0.34$ & $6.87(f) \pm 0.81$ \\
\hline 10 & $5.02(\mathrm{e}) \pm 0.42$ & $8.30(\mathrm{~d}) \pm 1.05$ & $58.84(d) \pm 0.57$ & $15.85(\mathrm{e}) \pm 0.62$ & $73.55(\mathrm{c}) \pm 0.40$ & $9.33(\mathrm{e}) \pm 0.16$ \\
\hline 25 & $11.54(\mathrm{~d}) \pm 0.28$ & $12.65(\mathrm{df}) \pm 0.31$ & $88.15(c) \pm 0.39$ & $22.79(\mathrm{~d}) \pm 0.29$ & $82.25(\mathrm{~b}) \pm 0.32$ & $18.87(\mathrm{~d}) \pm 0.56$ \\
\hline 50 & $21.06(c) \pm 0.89$ & $22.04(\mathrm{c}) \pm 0.76$ & $90.66(b) \pm 0.11$ & $37.62(\mathrm{c}) \pm 1.12$ & $91.34(\mathrm{a}) \pm 1.15$ & $36.36(\mathrm{c}) \pm 0.11$ \\
\hline 100 & $40.41(b) \pm 0.47$ & $42.18(b) \pm 0.48$ & $91.65(b) \pm 0.27$ & $68.66(b) \pm 0.80$ & $93.88(\mathrm{a}) \pm 0.24$ & $53.93(b) \pm 0.06$ \\
\hline 200 & $60.32(a) \pm 0.19$ & $66.16(a) \pm 1.36$ & $93.94(a) \pm 0.12$ & $93.47(\mathrm{a}) \pm 1.78$ & 96.33 (a) \pm 1.08 & $79.07(\mathrm{a}) \pm 0.37$ \\
\hline
\end{tabular}

NB: In a column means followed by common letters in parenthesis are not significantly different at $5 \%$ level by DMRT. Data are mean \pm SE values of three replications.

Table 4. Cytotoxicity of different fractions of B. lacera collected from JU campus and the Sundarbans



Note: Vincristine sulphate used as a positive control. 
Phytochemical study of Blumea lacera showed the presence of carbohydrates, flavonoids, trace amount of alkaloids, some glucosides, terpenoids and steroids in the polar fraction of B. lacera collected from JU campus and the Sundarbans. Ethyl acetate and methanol fractions of JU sample had strong scavenging of DPPH free radical with low ctytotoxicity than that of the sundarbans sample. Thus it is important to carry out extensive phytochemical and pharmacological studies on the ethyl acetate and methanol fractions of JU sample to eventually find out new bioactive compound.

Acknowledgement: The authors would like to express their gratitude to University Grants Commission (UGC) for providing the research fund and Professor Muhammad Ali Akond of Department of Botany, Jahangirnagar University for providing the laboratory facilities for conducting antibacterial assay.

\section{REFERENCES}

Abercrombie, M., Hickman, C.J.and Johnson, M.L. 1966. A Dictionary of Biology. London: Penguin Reference Books.

Agarwal, R. 1995. Triterpenoid and phenylated phenol glycosides from Blumea lacera. Phytochemistry. 38: 935-938.

Ahluwalia, K.S. 1968. Medicinal plants of Kerala-V. Nagarjuna, 11: 363-369.

Aoshima, H., Tsunoue, H., Koda, H. and Kiso, Y. 2004. Aging of whiskey increases 1,1-diphenyl2-picrylhydrazyl radical scavenging activity. J. Agric. Food Chem. 52: 5240-5244.

Bhaumik, U.K., Kumar, D.A., Selvan, V. T., Saha, P., Gupta, M. and Mazumder, U.K. 2008. Antioxidant and free radical scavenging property of methanol extract of Blumea lanceolaria leaf in different in vitro models. Pharmacologyonline, 2: 74-89.

Binns, S.E., Arnason J.T. and Baum, B.R. 2002. Phytochemical variation within populations of Echinacea angustifolia (Asteraceae). Biochem. Syst. Ecol., 30: 837-854.

Blois, M.S. 1958. Antioxidant determinations by the use of a stable free radical. Nature, 181: 1199-1200.

Brand-Williams, W., Cuvelier, M. and Berset, C. 1995. Use of free radical method to evaluate antioxidant activity. Food Sci. Technol. 28(1): 25-30.

Dev, H.S. 2002. Textbook of Pharmacognosy. 2nd edn. pp. 342. Acharcha Press, New Delihi.

Dickinson, C.I. 1963. British Seaweeds. The Kew Series.

Espin, J.C., SolerRivas, C. and Wichers, H.J. 2000. Characterization of the total free radical scavenging capacity of vegetable oils and oil fractions using 2,2-diphenyl-1-picrylhydrazyl radical. J. Agric. Food Chem. 48: 648-656.

Evans, W.C. 1989. Trease and Evan's Text book of Pharmacognosy. 13th edn. pp. 546. University Press, Cambridge.

Gayake, 2012. Plants used in medicine folklore of Ahmadnager distict, Maharastra. J. Pharmaceutical Education Res., 3: 19-24.

Ghani, A. 1998. Medicinal Plants of Bangladesh. 3rd edn. pp. 1-7, 215. The Asiatic Society of Bangladesh.

Ghani, A. 2003. Medicinal Plants of Bangladesh with Chemical Constituents and Uses. 2nd edn. pp. 603. Asiatic Society of Bangladesh., Dhaka.

Hossain S.J., Tsujiyama, I., Takasugi, M., Islam, M.A., Biswas, R.S. and Aoshima, H. 2008. Total phenolic content, antioxidative, anti-amylase, anti-glucosidase, and anti-histamine release activities of Bangladeshi fruits. Food Sci. Technol. Res. 14: 261-268. 
Phytochemical composition, antioxidant activity and cytotoxicity of Blumea lacera Linn.

Jha, R.R. and Verma, S.K. 1996. Ethnobotony of Sauria Paharias of Santhal Pargana, Bihar: Indian Medicinal plants. Ethnobotany, 8: 31-35.

Kumarasamy, Y., Byres, M., Cox, P.J., Jaspars, M., Nahar, L. and Sarker, S.D. 2007. Screening seeds of some Scottish plants for free-radical scavenging activity. Phytother. Res. 21: 615621.

Kupchan, S.M. and Tsou, G., 1973. Tumor inhibitors. A new antileukemic simaroubolide from Brucea antidysenterica. J. Org. Chem. 38: 178-179.

Meyer, B.N., Ferrigni, N., Putnam, J.E., Jacobsen, L.B., Nichols, D.E. and McLaughlin, J.L. 1982. Brine shrimp: a convenient general bioassay for active plant constituents. Planta Med. 45: 31-34.

Moshi, M.J., Innocent, E., Magadula, J.J., Otieno, D.F., Weisheit, A., Mbabazi, P.K. and Nondo, R.S.O. 2010. Brine shrimp toxicity of some plants used as traditional medicines in Kagera Region, north western Tanzania. Tanzania J. Health Res., 12:1.

Pandit B.R., Kotiwar O.S., Oza R.A. and Kumar R.M. 1996. Ethnomedicinal plant lore from Gir forest Gujarat. Adv. Plant Sci., 9 (1): 81-84.

Pattewar, A.M., Dawalbajea, A.B., Gundalea, D.M., Pawarb, P.B., Kavtikwara, P.G., Yerawara, P.P., Pandharkara, T.M. and Patawara, V.A. 2012. Phytochemistryical and Anthelmintic Studies on Blumea Lacera. Indo Global J. Pharmaceutical Sci., 2(4): 390-396.

Prajakta P.P, Vakil, B.V., Sane, R.T. and Datar, A.G. 2013. Phytochemical profile and antioxidant activity of the essential oil from Blumea eriantha D.C. Int. J. Pharmacy and Pharmaceutical Sci, 5(1): 404-413.

Pratap, S.U. and Parthasarathy, R. 2012. Comprative evaluation of Blumea lacera var. lacera and Blumea eriantha D.C. for mushroom tyrosinase inhibitory activity. Int. J. Pharm. Drug Res., 1(1\&2): 1-8.

Rao, B. 1977. Flavenoids from Blumea lacera. Planta Med. 31; 235-237.

Roy, J., Kuddus, M.R., Begum, B. and Hasan, C. M. 2012. Evaluation of analgesic, cytotoxic and antioxidant activities of Blumea membranacea D.C. Int. J. Pharm. Bio. Sci. 3(4): 566 - 572.

Sofowora, A. 1993. Medicinal plants and traditional medicine in Africa. pp.289. Spectrum Books Ltd, Ibadan, Nigeria.

Tiwari, P., Saluja, G., Pandey, A.S. and Sharma, N. 2012. Isolation and biological evaluation of some novel phytoconstituents from Blumea lacera (Burn F.) D.C., Int. J. Pharmacy and Pharmaceutical Sci, 4(4): 148-150.

Uddin, S.J., Grice, I.D. and Tiralongo, E. 2011. Cytotoxic effects of Bangladeshi medicinal plant extracts. Evidence-Based Complementary and Alternative Medicine.

Varandani, B.P. 1969. Indigenous therapy for piles. The Indian Practitioner, 9: 545-547.

Wagenen, B.C.V., Larsen, R., Cardellina, J.H., RanDazzo, D., Lidert, Z.C. and Swithenbank, C. 1993. Ulosantoin, a potent insecticide from the sponge Ulosa ruetzleri. J. Org. Chem. 58: 335-337.

Zhu, L. and Tian, Y. 2011. Chemical composition and larvicidal effects of essential oil of Blumea martiniana against Anopheles anthropophagus. Asian Pacific J. Trop. Med., 4(5):371-374. 